\title{
Notas sobre los aspectos
}

\section{sociales y económicos \\ de los "Regímenes intermedios". \\ El caso de Bolivia*}

Michal Kalecki, eminente economista polaco, nació en Lodz, Polonia,en I 899. A fines de la década de 1930 ingresó a la Universidad de Oxford, donde se desempeñó hasta fines de la Segunda Guerra Mundial. En 1946 ingresó a la División de Asuntos Económicos de las Naciones Unidas. Volvió a Polonia en 1955 como Vicepresidente de la Comisión de Planificación. Luego fue nombrado profesor de la Escuela Central de Planificación y Estadistica de Varsovia. En 1968 se acogió a la jubilación $y$ falleció el 17 de abril de 1970 en Varsovia. Entre sus libros traducidos al español figuran "Teoria de la Dinámica Económica" e "Introducción a la Teoria del Desarrollo de la Economía Socialista" publicados por el Fondo de Cultura Económica de México.

MARCIN KULA, joven historiador polaco, se doctoró en Historia Económica en Ig68. Actualmente trabaja como investigador de la Historia Económica de la América Latina en la Academia Polaca de Ciencias. Ha publicado recientemente una obra titulada "Comienzos de la esclavitud negra en el Brasil" (1970).

I. La historia ha mostrado que es poco probable que la pequeña burguesía y los campesinos ricos ejerzan el papel de clase dirigente. En toda oportunidad en que los vuelcos sociales han permitido a los representantes de estas clases subir al poder, invariablemente han servido los intereses de la gran burguesía (aliada a menudo con los remanentes del sistema feudal), pese a que hay una contradicción básica entre los intereses de la pequeña burguesía y los del gran capital. Basta mencionar el desplazamiento de las empresas pequeñas por las grandes.

¿Existen hoy condiciones específicas que favorezcan la emergencia de gobiernos que representen los intereses de la pequeña burguesía (incluyendo aquí también el estrato correspondiente del campesinádo)? Parecería que tales condiciones se dan actualmente en muchos países subdesarrollados:

* Nota de la Redacción: El presente artículo fue el último escrito por el prestigioso economista polaco prof. Michal Kalecki, fallecido en 1969 , y traducido al español por don Oscar Lizama León $y$ don Julio Vidal, ambos de la Universidad de Concepción —Chile. 
M. Kalecki y Marcin Kula / Notas sobre los aspectos sociales y económicos...

i) Al momento de Iograr la independencia, la pequeña burguesía es muy numerosa, mientras que las grandes empresas están controladas predominantemente por extranjeros, con sólo una pequeña participación de capitalistas locales.

ii) Las modalidades de intervención económica gubernamental están hoy bastante generalizadas. Aparte del caso obvio de los países socialistas, la intervención económica del estado juega un papel importante en los países capitalistas desarrollados.

iii) Es posible obtener capitales extranjeros también a través de créditos otorgados por los países socialistas.

2. En el proceso de emancipación política - especialmente si ésta no va acompañada por conflictos armados- los representantes de la pequeña burguesía ascienden al poder de un modo natural. Para mantenerTo deben:

a) lograr la emancipación no sólo política, sino también económica, es decir, una independencia frente al capital extranjero.

b) llevar a cabo una reforma agraria.

c) asegurar un continub crecimiento económico; este último punto está relacionado en forma directa con los dos anteriores.

Al tratar de limitar la influencia extranjera, el gobierno de la pequeña burguesía se enfrenta a un conflicto con los grupos "compradores". Al llevar a cabo la reforma agraria, el gobierno choca con los propietarios feudales. Sin embargo, puede no estar necesariamente inclinado a desafiar a la gran burguesía local. La alianza con esta clase dentro de la estrategía de desarrollo económico, podría llevar fácilmente a la repetición de un modelo histórico ya conocido: la sumisión final de la pequeña burguesía a los intereses del gran capital. Esto, sin embargo, se evita gracias a la debilidad de la gran burguesía local, y por su inhabilidad para ejercer el papel de "empresario dinámico" en gran escala. Las inversiones básicas para el desarrollo económico deben por tanto ser ejecutadas por el Estado, lo que conduce directamente hacia un modelo de amalgamación de los intereses de la pequeña burguesía con el capitalismo de Estado.

La realización de este modelo se ve facilitada por la participación del Estado en la administración de la economía, fenómeno característico de nuestra era. Una gran parte de la población mundial vive hoy en economías socialistas centralmente planificadas. Pero también en los países 
EST U D I OS I N T E R N A C I O N A L E S capitalistas desarrollados prevalece una cierta medida de intervencionismo estatal, el cual se propone, al menos, prevenir las crisis cíclicas. Hoy día, somos todos "planificadores" aunque muy diferentes en carácter. No es extraño, así, que los países subdesarrollados, esforzándose por expandir su potencial económico tan rápido como sea posible (mientras que la preocupación principal de los paises capitalistas desarrollados es la plena utilización de la capacidad productiva disponible) tiendan a efectuar planes de desarrollo económico. El próximo paso es llevar a cabo un gran volumen de inversión en el sector público, puesto que, como la experiencia lo ha mostrado, la iniciativa privada no puede asegurar un adecuado volumen de inversiones con una estructura apropiada. Por consiguiente, el capitalismo de Estado está directamente relacionado con una planificación de uno u otro tipo, la que los países subdesarrollados difícilmente pueden dejar de lado hoy.

La evolución en esta dirección podría ser neutralizada por la presión de países imperialistas, empeñados en condicionar en forma adecuada los créditos que otorgan. Como los países subdesarrollados necesitan un cierto flujo de capitales extranjeros, las presiones de esta clase podrían ser altamente efectivas en transformar los gobiernos de la pequeña burguesía en herramientas serviles de la gran burguesía aliada con la clase feudal. Aparte de la victoria "ideológica", los países imperialistas lograrían una mejor base de apoyo para defender sus inversiones "antiguas" en los países subdesarrollados, y para efectuar "nuevas" expansiones en esta esfera. Sin embargo, la posibilidad de obtener créditos de los países socialistas constituye un obstáculo significativo a estas presiones imperialistas. Su efecto se refleja no sólo en el monto del capital realmente recibido por los países subdesarrollados desde esta fuente, sino también en el fortalecimiento de su posición de regateo, negociando con las potencias financieras capitalistas. La competencia con los países socialistas para influir sobre los "regímenes intermedios" fuerza a estas potencias a otorgar créditos sin condiciones relativas a la política económica interna, aunque los gobiernos imperialistas tratan de obtener lo más posible en este respecto.

3. Es necesario analizar ẹn forma más detallada el sistema social, en el que la pequeña burguesía coopera con el capitalismo de Estado. Sin duda, este sistema es altamente ventajoso para la pequeña burguesía y los campesinos ricos; el capitalismo de Estado concentra la inver- 
M. Kalecki y Marcin Kula / Notas sobre los aspectos sociales y económicos... sión en la expansión del potencial productivo del país. No hay, por consiguiente, peligro de que se elimine a las empresas pequeñas, lo cual es un rasgo característico de la primera etapa de industrialización bajo el sistema del laissez-faire. Además, el desarrollo rápido de empresas estatales crea ocupaciones ejecutivas y técnicas a los jóvenes ambiciosos de la numerosa clase gobernante. Finalmente la reforma agraria, que no es precedida por una revolución agraria, es conducida de un modo tal que la pequeña burguesía que explota directamente a los campesinos pobres - es decir, los prestamistas e intermediarios- mantiene su posición, mientras el campesinado rico obtiene beneficios considerables en el proceso.

Los antagonistas de la clase gobernante son: por arriba, la gran burguesía, aliada con el capital extranjero y los propietarios feudales; por abajo, los pequeños propietarios y los campesinos sin tierras, así como también la población urbana pobre: trabajadores de pequeñas industrias y cesantes o casualmente empleados, principalmente inmigrantes del campo en busca de fuentes de mantención. Por otro lado, los trabajadores de "cuello blanco" y los poco numerosos trabajadores de las grandes empresas - quienes, en los paises subdesarrollados, se encuentran en una posición privilegiada, comparados con los trabajadores pobres urbanos y rurales- se encuentran frecuentemente aliados con la pequeña burguesía, especialmente cuando son empleados de las empresas estatales.

4. En cuanto a las clases "altas" antagónicas, los elementos feudales están generalmente privados de significación política debido a la reforma agraria. Ellos podrían retener parte de sus tierras a través de ventas ficticias a sus parientes (como una forma de evadir los límites fijados) pero esto no los deja en una posición fuerte en la vida política. y social del país.

Por otro lado, la actitud hacia la gran burguesía puede extenderse desde una nacionalización de gran alcance (corrientemente con compensación) hasta una mera limitación del alcance de la inversión privada, unida a ensayos (por lo general más bien ineficientes) para adaptar su estructura a los objetivos globales de desarrollo.

La importancia política de la gran burguesía local corresponde a estas variantes. En todo caso su inclinación a oponerse al gobierno se ve 
ES.TU DIOS I N T ER N A C I O N A L ES

frenada por el temor ante el proletariado rural y urbano, del cual está efectivamente separado por la pequeña burguesía gobernante.

La elección de una variante particular al tratar con los grandes capitalistas está determinada, no tanto por la ideología de la clase gobernante, cuanto por la fuerza de los primeros. Sin considerar las condiciones económicas existentes, uno podría esperar más "socialismo" de Nehru que de Nasser. Sin embargo, fue a la inversa, porque al momento de ganar la independencia política, la gran burguesía era más fuerte en la India que en Egipto.

5. Al menos potencialmente, los pobres urbanos y rurales son antagónicos con la clase gobernante, ya que ellos no se benefician con el cambio del sistema social descrito anteriormente, y ganan relativamente poco con el desarrollo económico. La reforma agraria se conduce de tal forma que la mayor proporción de la tierra disponible va a pasar a manos de los campesinos ricos y medianos, mientras los pequeños propietarios y el proletariado rural reciben muy poca. Se hacen esfuerzos insuficientes para liberar a los campesinos pobres de las garras de los prestamistas e intermediarios, así como para elevar los salarios de los trabajadores del campo. La situación agraria resultante es uno de los factores que limitan la producción agrícola en el curso del desarrollo, ya que bajo las relaciones agrarias prevalecientes las granjas pequeñas son incapaces de expandir su producción. Este es también el caso de las granjas mayores cultivadas por arrendatarios. El retraso de la agricultura respecto del crecimiento económico general, acarrea una oferta inadecuada de alimentos $y$ un aumento en sus precios, lo cual es nuevamente desventajoso para los "hijastros" del sistema. Aun' si el ingreso real global de estos estratos no declina, a raíz del aumento del empleo, no muestra tampoco un crecimiento apreciable.

Aunque no existe razón para que los estratos más pobres de la sociedad estén contentos, no constituyen un peligro para este sistema, al menos por ahora. Los proletarios rurales y los campesinos pobres están controlados por una cierta forma de oligarquía local, compuesta por la pequeña burguesia (intermediarios y prestamistas), campesinado rico y pequeños terratenientes. La población urbana sin un empleo estable -e incluso los artesanos y trabajadores en pequeñas industrias- tảmpoco son peligrosos, porque están permanentemente amenazados por el desempleo y es muy difícil que se organicen. 
M. Kalecki y Marcin Kula / Notas sobre los aspectos sociales y económicos...

En este contexto puede comprenderse fácilmente la represión en contra de los comunistas observada en algunos "regímenes intermedios" No se trata aquí de un problema de competencia entre ideologías paralelas; los comunistas son, al menos potencialmente, los portavoces de los pobres, urbanos y rurales, y la pequeña burguesía siente un temor justificado ante su activación política.

Es verdad que esta pequeña burguesía y los campesinos más prósperos no son realmente ricos; en muchos casos su standard de vida es más bajo que el de los trabajadores de los países desarrollados. Pero en comparación con los campesinos pobres, quienes también afluyen a las ciudades como cesantes o artesanos malamente pagados, el pequeño burgués es un "potentado" con mucho que perder. En este contexto no es coincidencia que los gobiernos en cuestión favorezcan la religión - aun hasta el punto de adoptar una religión oficial - y muestren una tendencia hacia la expansión externa, asociada con un militarismo.

6. En el campo internacional, la posición interna de la pequeña burguesía gobernante encuentra su contrapartida en la política de neutralidad frente a los dos bloques: una alianza con cualquiera de los dos reforzaría el antagonismo correspondiente dentro del país. Al mismo tiempo, la neutralidad es muy importante en relación a los créditos extranjeros mencionados anteriormente.

Los "regímenes intermedios" son los astutos terneros proverbiales que chupan de dos vacas: cada bloque les da ayuda financiera, compitiendo con el otro. De este modo ha sido posible el "milagro" de que se obtengan créditos de Estados Unidos sin condiciones referentes a la política económica interna.

Debe notarse, sin embargo, que los créditos extranjeros son de gran importancia para los "regímenes intermedios". El retraso de su agricultura en el curso del desarrollo global —debido en gran medida a factores institucionales- trae como consecuencia un déficit en la disponibilidad de alimentos, que el Estado cubre en parte con importaciones (puesto que los pobres no deben ser empujados a los extremos). Esto crea dificultades adicionales a la de suyo forzada balanza de pagos, cuyo remedio es buscado en los créditos extranjeros.

Esta posición en las relaciones internacionales protege a los "regimenes intermedios", como se ha señalado anteriormente, de las presiones de las potencias imperialistas, que buscan la restauración de las 
ESTUDIOS INTERNACIONALES

reglas "normales" de los elementos del gran capital, en las cuales el capital extranjero jugaria un apreciable papel (aunque más limitado que en el pasado). Sin estas presiones externas, es altamente improbable que la amalgama de la pequeña burguesía y el capitalismo de Estado pueda ser destruida y restablecido el capitalismo clásico.

Lo que antecede fue publicado en Polonia a fines de ig64. Aunque Indonesia no contradijera en ese momento el modelo de "régimen intermedio" descrito, no ha sido, sin duda, el ejemplo más representativo, por las siguientes razones:

a) En su politica económica, Indonesia se encontraba considerablemente atrás respecto de un "régimen intermedio" típico. La reforma agraria fue en realidad claramente inefectiva, y cambió muy poco las condiciones agrarias de Indonesia. Tampoco hizo el gobierno ningún esfuerzo consistente en términos de industrialización y planificación; en particular, permitió que se desarrollara una inflación violenta. Más aún, el gobierno consideró esencial otorgar prioridad a la "integración nacional" (inclusive respecto de las peticiones de West Irian y Northern Borneo) sobre los problemas económicos y sociales.

b) Por otro lado, la política exterior de Indonesia fue más antimperialista y anticolonialista que la de otros "regimenes intermedios". Este radicalismo estaba asociado en parte a los reclamos territoriales mencionados arriba (en particular la confrontación con Malasia) pero tuvo un carácter definitivamente general.

c) El subproducto de la lucha por la incorporación de West Irian y de la "confrontación con Malasia" fue la expansión del ejército - lo que causó un gravamen considerable a la economía- y el aumento del poder político de sus más altos jerarcas.

d) En contraste con otros "regímenes intermedios", Indonesia tenía un partido comunista muy numeroso. Este estaba enraizado principalmente en el descontento de los campesinos pobres y trabajadores agrícolas. Sin embargo, cooperaba con el régimen sobre la base de sostener su política antiimperialista, sin Iuchar decididamente en contra de su negligencia frente a los problemas económicos y sociales, y sin una preparación para un enfrentamiento con la clase media reaccionaria asociada estrechamente con el ejército. Es obvio que el partido comunista representó aquí una amenaza mucho mayor para esas clases que en 
M. Kalecki y Marcin Kula / Notas sobre los aspectos sociales y económicos...

otros "regímenes intermedios". Amenaza que era, sin embargo, más potencial que real.

Es la situación bosquejada arriba la que creó las bases para el desarrollo subsiguiente en Indonesia. La historia completa de los sucesos del $3^{0}$ de septiembre de ig65 no ha sido escrita todavía. Aun así, está claro que los comunistas no intentaron tomar el poder y que en realidad estos hechos jugaron el papel de un Reichstagsfeuer. El terror anticomunista que siguió fue sin precedentes, aun en la historia de las contrarrevoluciones: en el espacio de unos pocos meses fueron asesinadas alrededor de 400.000 personas. Los altos mandos del ejército, representando principalmente a la clase media reaccionaria y a los campesinos ricos, o aun elementos semifeudales, eliminó así la "anomalía" de un partido comunista numeroso en un régimen intermedio.

También la política exterior volvió a lo "normal". Aunque, como se ha dicho arriba, el ejército derivó su poderío de la política de "confrontación con Malasia", han sido ellos quienes ahora han terminado con esta política. En general, el radicalismo de la política exterior de Indonesia ha terminado aunque, al menos por ahora, no ha sido abolida la política de no alineación.

De los problemas económicos, enfatizados por el nuevo gobierno, se está culpando a los predecesores. Sin embargo, las conclusiones sacadas de la catastrófica situación económica no apuntan en absoluto hacia una mayor planificación o reforma agraria. El terror que ha desatado no sólo contra los comunistas sino contra los radicales en general, es considerado probablemente como un substituto para las políticas económicas y sociales progresistas.

\section{Bolivia: un "Régimen Intermedio" en América Latina}

I. Uno de los coautores de este artículo, M. Kalecki, usa el término "Regímenes Intermedios" para caracterizar a una serie de países subdesarrollados que, junto con lograr su independencia después de la segunda guerra mundial, impusieron serias limitaciones a los intereses extranjeros, llevaron a cabo una reforma agraria, iniciaron un proceso de desarrollo económico con una participación importante del gobierno y que, en términos estrictos, no pueden ser considerados capitalistas ni socialistas*.

* En un artículo publicado primero èn Polonia en 1964 ; una versión ampliada, cubriendo los sucesos de Indonesia, apareció en polaco en 1966 y en inglès en "Coexistence" No 1.1967 . 
E S T U D I O S I N T E R N A C I O N A L E S

Kalecki planteó que el gobierno en estos países representa los intereses de la pequeña burguesía y de los campesinos ricos o medianamente ricos, ligados con el capitalismo de Estado. Los directivos del sector gubernamental provienen también, en su mayor parte, de las clases medias. Los antagonistas de esos gobiernos, en su nivel superior, son los remanentes del feudalismo, que subsisten después de la reforma agraria, y la gran burguesía local cuyo peso ha sido a menudo reducido por la nacionalización. Los antagonistas desde abajo son los campesinos pobres y los trabajadores agrícolas que se beneficiaron en general muy poco con la reforma agraria, y los pobres urbanos: gente sin empleo estable, artesanos y trabajadores de pequeñas empresas. Los trabajadores de "cuello blanco" y los trabajadores en grandes empresas -quienes están en una posición más bien privilegiada, comparada con la de los pobres urbanos y rurales - frecuentemente sostienen a los regímenes intermedios, especialmente cuando están empleados en empresas estatales.

La política externa de no alineación de los "regimenes intermedios" ha sido, en cierto sentido, una contrapartida para defender la política interna. Al mismo tiempo, la neutralidad respecto de los dos bloques es muy importante desde el punto de vista del reforzamiento de una posición de regateo en las negociaciones de los créditos externos o de la asistencia técnica.

2. Los países a que se ha hecho referencia, están situados en el Lejano y Medio Oriente, y en Africa. Son India y Egipto los ejemplos más característicos. En Latinoamérica todos los países, al menos formalmente, obtuvieron su independencia mucho antes y la segunda guerra mundial no cambió básicamente las condiciones que allí existían. El surgimiento de un "régimen intermedio". en Bolivia, en I952 tuvo un carácter diferente al de los países antes mencionados. La "revolución" bajo la dirección de Paz Estenssoro, se efectuó como resultado de la alianza de ciertas fuerzas opuestas a la oligarquía, basada ésta en las empresas mineras de estaño y en los propietarios feudales. Esta alianza se componía de algunos nacionalistas radicales de la "intelligentsia", de oficiales del ejército, y de mineros del estaño, clase muy pobre y explotada, reclutados de entre los pobres rurales. Debe señalarse que en el campo prevalecía un feudalismo típico que no producía para la exportación; y que no existia una industria manufacturera en gran escala. 
M. Kalecki y Marcin Kula / Notas sobre los aspectos sociales y económicos...

Los comienzos de la "revolución" se caracterizaron por dos medidas tipicas de un régimen intermedio: nacionalización de las minas de estaño, que estaban formadas por una combinación de capital extranjero y local, y reforma agraria. Es cierto que esta última no fue de ningún modo perfecta, especialmente en su ejecución. Pero en este puntọ Bolivia no difiere mucho de otros "regimenes intermedios". Esto tuvo dos consecuencias que coinciden con lo ocurrido en los paises antes mencionados: a) creó un estrato, más bien vigoroso, de campesinos ricos y medianamente ricos; b) los propietarios feudales dejaron de ser una clase dirigente, transformándose en un ala derechista de oposición, más bien ineficaz, contra el régimen. El gobierno inició subsecuentemente un plan de desarrollo económico.

3. Como veremos, la participación de los mineros bolivianos del estaño y sus gremios en los acontecimientos de 1952, reemplazó en cierto sentido la lucha por la independencia, como fuerza motriz. Como resultado, los mineros estuvieron representados en el gobierno por su líder, y sus salarios fueron aumentados. A raíz de la inflación subsiguiente - la cual se produce por diversas razones que no analizaremos aquí que fue "curada" por un "programa de estabilización" inspirado por Ee.uU. los salarios reales de los mineros cayeron a su nivel previo, sumamente bajo. (La justificación de esto, argumentando en base a los altos costos de producción de los minerales del estaño boliviano, es falsa, porque se podría haber aplicado un subsidio financiado por el presupuesto general; sin embargo el "programa de estabilización" tuvo, en términos generales, un carácter de tipo laissez-faire). Esto indujo a movimientos huelguísticos que fueron rudamente suprimidos. El resultado final fue la toma del poder por una junta militar presidida por el general Barrientos en 1964 , que continuó la represión contra los mineros.

En este punto, podría surgir la impresión de que este "régimen intermedio" se desvió del molde tradicional. Sin embargo, fue el caso opuesto. Lo que constituyó la anomalía para un "régimen intermedio" fue la participación fuerte de los mineros en la primera fase del "gobierno revolucionario". Lo que sucedió con estos mineros, posteriormente, es análogo al trato rudo que reciben los comunistas en general en los regímenes intermedios, ya que ellos eran, al menos potencialmente, los portavoces de los pobres urbanos y rurales*. Visto de este modo, el vuelco

*Ibidem, pp. 3-4. 
contrarrevolucionario hacia la derecha fue en el hecho una "normalización" de un "régimen intermedio". Es cierto, sin embargo, que este vuelco fue precipitado por la influencia norteamericana.

4. En contraste con otros "regímenes intermedios", Bolivia no practicó la política de no-alineación, si abstraemos algunos intentos en la primera etapa de la "revolución". En realidad, podía darse por satisfecha de que los EE. UU. no interfirieran drásticamente en su revolución: diferencia sorprendente respecto del tratamiento a Guatemala bajo Arbenz. ¿Cuál fue la razón para esta actitud tolerante? Primero, fue importante el que ninguna empresa con relaciones poderosas en los EE. UU como la United Fruit Co., estuviera comprometida en Bolivia. Los intereses de la minería no tenian conexiones poderosas, y la reforma agraria no interfirió en los intereses de las plantaciones norteamericanas, pues éstas no existían en el país. El absorber las minas de estaño nacionalizadas no era una proposición muy atractiva ya que, estando agotadas en grado considerable, tienen un costo de producción muy alto.

Además, por lo común los minerales son vendidos en el mercado norteamericano y no existen posibilidades de fundición en el país. Sin embargo, en los casos en que estaban disponibles recursos de materias primas prometedores, como por ejemplo, petróleo, se logró una concesión a las empresas norteamericanas en una etapa posterior. Sin embargo, la demanda interna boliviana fue cubierta por empresas dirigidas por el gobierno. Segundo, durante todo el período considerado, Bolivia dependió de la "asistencia económica" de los EE. uU. quien así pudo ejercer una influencia poderosa en el desarrollo interno.

No obstante, los minerales de estaño no han sido desnacionalizados ni la reforma agraria ha vuelto a su estado anterior. Después del nuevo coup d'etat de 1969 por el general Ovando Candia antiguo asociado de Barrientos, incluso las concesiones de petróleo fueron canceladas. Como saldo, el "régimen intermedio", que no puede confundirse con el socialismo ha sido mantenido, pese a que Bolivia permanece en la esfera de influencia norteamericana.

5. Una de las deducciones de lo anterior, es la explicación de la suerte del movimiento guerrillero del Che Guevara en Bolivia. Es claro que cuando eligió la región para sus actividades en Latinoamérica, Guevara no hizo un adecuado análisis de la realidad económica y social del "campo de batalla". El movimiento guerrillero tiene éxito en primer 
M. Kalecki y Marcin Kula / Notas sobre los aspectos sociales y económicos...

lugar en aquellas regiones en donde los campesinos pobres y trabajadores agrícolas son oprimidos por los propietarios feudales. El movimiento guerrillero clásico tiende a desarrollarse hacia una guerra campesina. Pero en Bolivia fue casi el reverso, lo que está simbolizarlo por la distribución de armas a los campesinos de la región de Cochabamba por el general Barrientos, contra las guerrillas.

Es cierto que existía la posibilidad teórica de que los mineros sostuviesen a las guerrillas, ya que su lucha contra el gobierno alcanzó su punto más alto en el período de actividad del Che Guevara (aunque independientemente de ella). De hecho, sin embargo, ellos no podían alimentar a las guerrillas. Aunque los mineros son reclutados de entre los campesinos pobres, ellos no son campesinos pobres. No producen alimentos. Por el contrario, aun sus acciones huelguísticas son difíciles, a causa de la posibilidad de que se les bloquee la oferta de alimentos. Sólo una alıanza de mineros y campesinos podría haber sido la base para una rebelión, pero esto era difícilmente posible: en 1952 los mineros, aliados con elementos radicales de la intelligentsia y de la oficialidad, efectuaron el derrocamiento de la oligarquía tradicional. La reforma agraria subsecuente trabajó en contra de la alianza de los mineros y campesinos en la próxima fase, aunque fue inadecuada. En esas circunstancias, la empresa de Che Guevara estaba condenada de antemano.

6. ¿Es Bolivia un ejemplo aislado de un "régimen intermedio" en Latinoamérica, o un modelo que se extenderá a otros países de ese subcontinente? Existe la tentación de descubrir los bosquejos de este modelo en la reciente "revolución" en el Perú, pero surgen algunas dudas, al menos en esta primera etapa. Es cierto que los oficiales de la Junta "revolucionaria" decretaron la nacionalización de los yacimientos petroliferos y también realizaron una reforma agraria de gran alcance. Sin embargo, esta última está siendo llevada a cabo, por ahora, sólo en el litoral norte donde están situadas las plantaciones de caña de azúcar, las que fueron nacionalizadas. Esto puede estar en cierta medida, dirigido contra el APRA, que es el organizador de los Sindicatos de los trabajadores de las plantaciones. En cuanto a las tierras en la sierra, que son del dominio de elementos feudales, el progreso es por ahora pequeño. Aparte de esto, existen aquí, en contraste con Bolivia, empresas industriales grandes con conexiones fuertes con los EE. UU. El ejemplo más promi- 
E S T U D I O S I N T E R N A C I O N A L E S nente es la producción de harina de pescado, que es uno de los items de exportación más importante.

Es probable que en muchos países latinoamericanos, la gran burguesía industrial, asociada con elementos feudales, sea ahora demasiado fuerte como para dejar la puerta abierta a un "régimen intermedio"; y que en estos países el capitalismo se desarrollará según el "modelo prusiano", manteniendo estrechas relaciones con las empresas norteamericanas. En efecto, una de las condiciones de aparición de "regímenes intermedios" en el Lejano y Medio Oriente, y en Africa, fue la debilidad de la gran burguesia industrial local, en relación a la muy numerosa pequeña burguesia*.

* En Bolivia, no existia una gran burguesia industrial, excluyendo la de los minerales de estano tradicionales tal como se ha dicho anteriormente. 